Taking ethics into account in farm animal breeding what can the breeding companies achieve?

Olsson, I. Anna S.; Gamborg, Christian; Sandøe, Peter

Published in:

Journal of Agricultural and Environmental Ethics

DOI:

10.1007/s10806-005-4494-6

Publication date:

2006

Document version

Publisher's PDF, also known as Version of record

Citation for published version (APA):

Olsson, I. A. S., Gamborg, C., \& Sandøe, P. (2006). Taking ethics into account in farm animal breeding: what can the breeding companies achieve? Journal of Agricultural and Environmental Ethics, 19(1), 37-46.

https://doi.org/10.1007/s10806-005-4494-6 


\title{
Taking Ethics Into Account in Farm Animal Breeding: What can Breeding Companies Achieve? ${ }^{1}$
}

\author{
I. A. S. Olsson ${ }^{1,2 *}$, C. Gamborg ${ }^{2}$ \& P. Sandøe \\ ${ }^{1}$ Institute for Molecular and Cell Biology, Porto, Portugal \\ ${ }^{2}$ Danish Centre for Bioethics and Risk Assessment, Royal Veterinary and Agricultural University, \\ Copenhagen, Denmark
}

*Corresponding author

\begin{abstract}
Animal welfare and the ethical issues it raises have been discussed intensively for a couple of decades. The emphasis has been on the direct effects of housing and husbandry, but more attention is now being given to problems originating in selective breeding. European attempts to adjust animal welfare legislation to deal with these problems have been largely unsuccessful, but the fact that selective breeding can introduce welfare problems continues to place an ethical responsibility on the animal breeding industry. Since breeding decisions are made centrally and, increasingly, internationally, strategic change is only likely to occur if it is embedded in an international agreement of some kind. The aim of this paper is to describe the key ethical issues facing animal breeding and assess the suggestion that the breeding industry itself can deal with ethical issues by means of an ethical code. Results from recent projects involving commercial breeding enterprises are presented.
\end{abstract}

Keywords: Animal welfare, Values, Sustainability, Animal production, Biotechnology

\footnotetext{
${ }^{1}$ The reference of the printed version is:

I. A. S. Olsson, C. Gamborg \& P. Sandøe (2006): Taking Ethics into Account in Farm Animal Breeding: What can the Breed Companies Achieve? Journal of Agricultural and Environmental Ethics 19(1): 37-46

The definitive version is available at http://www.springerlink.com/content/j42117w140p51267/
} 


\section{Introduction}

Productivity in livestock farming rose dramatically throughout the developed world during the second half of the twentieth century as a result of efficient breeding programmes, improved understanding of animal nutrition and disease control, and better designed housing systems. The growth rate and feed conversion efficiency of broiler chickens illustrate the changes vividly: between the early 1960s and the late 1990s the time needed to produce a slaughter-weight broiler fell from 80 to 40 days, and the required feed consumption halved (e.g. Christensen, 1998). This growth in productivity has added to human wealth. It has also allowed farmers to make effective use of the natural resources at their disposal. However, the narrow focus on production traits has had drawbacks. These include compromised animal welfare and loss of genetic diversity. Broader breeding goals have, of course, sometimes been maintained. The Nordic dairy cattle breeding programmes promote both production and health traits (Christensen, 1998). Elsewhere, in a number of species, an assortment of traits often appears in a 'total merit index', or TMI. More generally, it is clear that breeding companies are working towards balanced breeding goals incorporating functional traits. It would be naive, however, to imagine that we no longer need to enquire into the ethical implications of modern farm animal breeding practice. Indeed, quite apart from the issues associated with welfare and genetic diversity, new genetic and reproductive technologies raise questions about what may and may not be done to animals and their genomes - be that through traditional selective breeding or through the use of newer techniques such as transgenics. The key questions here concern the limits of acceptable practice in this area of technological development, and who should set these limits.

For several decades, animal welfare and other ethically significant aspects of animal production have been the subject of public debate in Europe. This debate is reflected in changes to animal protection legislation at both the national and European level, with EU directives now regulating the on-farm, transport and slaughter conditions of several farm animal species. In most parts of the livestock sector (such as animal production, slaughter and transport) and beyond, legislative measures have been shown to complement internal market regulation reasonably well. However, the regulatory framework has not been particularly effective in the farm animal breeding sector. European attempts to adjust legislation in response to the issue of animal welfare and breeding face two problems. First, it is not clear what the current legislation (i.e. Council Directive 98/58/EC on animals kept for farming purposes, which in effect regulates breeding) requires of the breeder. Second, it remains unclear how to ensure compliance with this kind of legislation - and the intentions that appear to lie behind it. According to the FAWC (2004) there is no case in which the legislation has been used successfully to restrict a breeding procedure. 
Besides legislation and market mechanisms, voluntary measures can, of course, be devised to meet public concerns. So far such measures have been few. Those that have appeared have not been adopted uniformly on a common platform. A European project that is now well underway (CODE-EFABAR) aims to develop a code of good practice for breeding companies. Before we assess the strengths and weaknesses of this approach, however, we want to outline some key concerns and describe one way of bringing some of these concerns into actual breeding practice.

\section{Ethics in farm animal breeding - key concerns}

To date, breeding programs have delivered animals that grow faster and yield more 'product', with obvious advantages for both farmers and consumers. But the negative effects of increased productivity are becoming increasingly apparent; and it is society's growing understanding of these effects that has raised questions about what is ethically acceptable in animal breeding.

\section{Breeding and animal health and welfare}

Health problems associated with breeding have been noted in several species (Rauw et al., 1998). In dairy cows, high milk yield is connected both with significantly raised levels of mastitis and reproduction problems. In broiler chickens, high growth rate causes leg problems (Christensen, 1998). Whether animal welfare is defined in terms of the animals' subjective experience or in terms of health and biological function (see Fraser and Duncan, 1997), these problems will involve reduced animal welfare. Welfare problems also arise in presently used production systems. Examples are feather-pecking in laying hens and tail-biting in pigs, both of which may be influenced by breeding. Breeding companies can play an important role in addressing welfare problems of both these types by defining broader breeding goals - goals that include not only production traits but also functional traits.

\section{Biodiversity}

Intensive selection leads to losses in genetic diversity when a few genotypes of particularly high breeding value are concentrated upon and put to heavy use. (Let us note in passing that decisions over the animals to be selected for reproduction are to a large extent taken by breeding companies and are principal determinants of the genetic diversity of livestock.) This danger is particularly great in dairy cattle, in which artificial insemination enables a few bulls to sire offspring all over the world. When less productive local breeds are 
replaced by high-yielding and thus more profitable breeds, genetic diversity is lost. Such diversity can be seen as a value in itself. Local breeds also have value as part of a cultural heritage. However, perhaps the most important attraction of maintained genetic diversity is the provision of a sort of insurance for the future: since we do not know what genes will be needed for future breeding goals, we should probably maintain as broad a genetic pool as possible.

\section{Resource use and environmental effects}

Resource use and the environmental impact of animal production are primarily determined by farm animals' capacity for efficient feed conversion. The more efficiently animals can convert locally available feeds (particularly those which cannot be used for human consumption), the more sustainable is the corresponding production system. Hence, by selecting for traits that improve feed conversion, breeders can promote environmental sustainability.

\section{Animal integrity and ethical limits to breeding}

Although they are important, animal welfare, biodiversity and environmental protection are not the only issues. This was demonstrated recently by public outrage at the very idea of breeding a featherless broiler chicken. Although the research team behind the bird argues such broilers are more resource-efficient and do not seem to suffer from welfare problems, most people feel there is something objectionable about breeding the bird. Featherless broilers lack one of the essential characteristics of birds: their integrity has been violated. While genetic selection is not in itself unacceptable, questions arise about the purpose for which animals are bred. Is it at all acceptable, ethically speaking, to alter the genome of animals solely according to the needs and desires of farmers and the market? Some would say 'no', as can be seen in the response of several animal protection associations to questions about the general acceptability of breeding endeavours (Kolar \& Rusche, 2003). Several respondents here believed breeding to be acceptable only when it brings about at improvements in the health and welfare of animals. But European farmers operate increasingly in a global market in which there is intense pressure is to keep costs low, and if non-European breeders continue to target productivity, European breeders may have little choice other than to follow suit. In this situation, a balanced policy would be to take health and welfare into account when continuing to breed for productivity and profitability. 


\section{Technologies}

Techniques used by breeders have also been subjected to ethical scrutiny. Breeding technologies used in addition to, or instead of, traditional mating range from established methods (e.g. artificial insemination) to newer, more controversial activities (e.g. cloning and transgenesis [cfr supra]). Many of the latter are still used only on an experimental basis, and examples of their successful application in farm animals are rare. Concerns over reproductive and genetic technologies are numerous: they include anxieties about welfare consequences for animals, risks to the environment and human health, interference with aspects of life which are not for humans to tinker with (that is, the allegation that we are 'playing God'), and the violation of genetic integrity (Sandøe and Holtug, 1998).

\section{Ethical considerations in practice: the example of Danish pig breeding}

We shall now discuss Danish pig breeding, since this demonstrates the way in which a concern like animal welfare is considered in actual breeding practice. Our discussion is based on material collected for a report on ethics in pig breeding prepared jointly by the Danish Centre for Bioethics and Risk Assessment and the Danish Bacon and Meat Council. The material was collected through site visits and interviews with scientific and technical personnel and breeders involved in Danish pig breeding.

Most Danish pig breeding occurs under the auspices of the Danish Bacon and Meat Council. Its breeding organisation DanAvl organises the breeding of four breeds (Landrace, Yorkshire, Duroc and Hampshire) in about 40 nucleus herds (9,500 sows) and 130 multiplier herds (35,000 sows) (Landsudvalget for Svin. 2004). All the herds are owned by private farmers; these farmers have a contract with DanAvl. These individual farmers decide which animals to select for further breeding. However, their success - and hence their business prospects - depends on their ability to meet defined breeding goals (Steen Petersen, personal communication).

Breeding goals are centrally defined but in close cooperation with pig producers and the meat industry. A goal is updated whenever there is sufficient evidence from different $R \& D$ projects to indicate that a change would be profitable. Economic consideration (producer profit) is the central criterion for including traits in the breeding goal or changing the assignment of weights. An exception can be made if the expected economic result of changing the breeding goal is approximately zero; then a trait can be included for ethical/welfare reasons (Ingela Velander, personal communication). The focus on economics does not necessarily exclude ethical and animal welfare considerations. Thus, recently, the trait "number of piglets born" was replaced by "number of piglets alive on day five". The latter trait, combining both litter size and survival, was introduced when it was recognised that selection for number of piglets born resulted in a 
considerable increase in perinatal piglet mortality (The National Committee for Pig Production, 2004). It is noteworthy that research and development has changed from focusing on production to the present strong emphasis on health and welfare related traits, with ongoing activities including breeding for longevity, health and maternal ability in sows (The National Committee for Pig Production, 2004).

Nevertheless, some of the interviewees were critical in their responses. The criticisms had above all to do with the direction of breeding. One critic, a pig production veterinarian, suggested implementing a quality control system with regular check-ups to keep track of undesirable developments, such as increased sow mortality and increases in certain diseases he had witnessed in his veterinary practice. One of the breeders was concerned over the imbalance caused when an increase in the number of piglets born is not matched by the sow's capacity to raise the piglets. Presently, fostering is unavoidable in purebred herds. Great strain is placed on sows that receive a litter of younger foster piglets when its own piglets are weaned. Common to these critiques is an underlying question about how, more systematically, to take into account animal welfare - and how to approach other ethical concerns.

\section{Handling the ethical issues: a code of good practice}

If our aim is to translate ethical issues, such as the issue of animal welfare, into action, the notion of sustainability may be useful. In this paper, we use the term 'sustainability' in a wide sense to indicate a general framework endorsed broadly by stakeholders and the rest of society for addressing ethical concerns relating to the management of natural resources.

Over the past six years no fewer than three European network projects involving scientists, NGOs (primarily animal protection organisations and consumers' organisations), and experts from outside science, including ethicists, sociologists and lawyers, have taken up the challenge of addressing animal welfare and other ethical issues in close collaboration with the breeding industry. The first of these projects (FAIP/ELSA) identified and clarified key concerns such as animal welfare, animal integrity, and loss of diversity. The second (SEFABAR) tried, within the framework of sustainability, to work out ways to take these potentially conflicting concerns into account in breeding programmes. This approach raised the breeders' awareness of how, practically, to deal with ethical issues. It also helped to identify the positions and priorities of different stakeholders. The third project (CODE-EFABAR), to be concluded in 2005, is developing a Code of Good Practice for animal breeding that can be signed up to by European animal breeding enterprises and organisations. This code is for practical use. It is therefore important, in developing it, not only to identify concerns but also to work out how they can be addressed: to examine how concerns expressed by different stakeholders can be balanced, and how to resolve conflicting priorities. 
Animal welfare issues, in combination with growing understanding of the undesired side effects of breeding programmes, have directed wider attention to the role of farm animal breeding. The three network projects just mentioned grew out of a need, felt by the breeders, to understand the ethical issues so as to be able to deal with them. Breeders are aware that their credibility depends on their ability to enter into productive dialogue with, and react to the concerns expressed by, stakeholders throughout Europe.

In the network projects, ways of accounting for various ethical aspects of farm animal breeding have been developed. This has been particularly useful in bringing together the factual issues and any identified underlying values. Undoubtedly, in a society increasingly concerned about the ethics of present-day management of sentient animals and natural resource use, it is important that breeders take responsibility for their part of the production chain. The main questions concern ways in which breeders can respond to ethical issues in their actual breeding practices, influence future developments, and enter into a dialogue with the other stakeholders.

Ethics is a wide concept and if it is to be applied in practice it will be important to define specific concerns and to translate them into breeding goals. This is where the notion of sustainability can be useful: it helps consumers and other stakeholders to communicate their concerns to a wider audience in a clear way and also helps breeders to present their achievements in a more understandable manner (Gamborg and Sandøe, in press). A great advantage of putting sustainability in the foreground is that it obliges decision makers, in and beyond the breeding sector, to combine concerns like health, welfare and the preservation of genetic resources in a unified perspective (Gamborg and Sandøe, in press). Important sustainability concerns identified in the SEFABAR project include productivity, product quality, animal health, wise use of resources, cost efficiency, consumer safety, animal welfare, environmental protection, competitiveness, animal integrity and biodiversity.

The network projects have shown that interest groups do not always agree over definitions and certainly do not agree on the prioritisation of concerns. The breeding associations emphasise productivity and product quality. For some of the animal protection associations, on the other hand, animal welfare should be the main focus of farm animal breeding. To some extent, these conflicts can be resolved through technological compromise: with a sophisticated approach, it may be possible to include both production and health and welfare in a breeding goal. The network projects have provided examples of these: for example, the total economic gain from selection for a TMI in dairy cattle has been shown to be $10-25 \%$ more than that from a selection for a single trait despite a reduced gain in milk production levels (FAWC, 2004). By contrast, there appears to be no apparent economic incentive to avoid leg problems in broiler chickens, and hence here there is little economic incentive to take into account animal welfare in the breeding goal. In cases where compromise is not possible, transparency about the various positions is important for credibility. 
While this initiative clearly shows that the European breeders are in principle willing to work with noncommercial factors (animal welfare, and environmental and other sustainability issues), the question is to what extent they will be able to do so in practice without jeopardising their own economic viability. For those in the breeding sector, breeding is above all an economic activity which needs to deliver profit. Breeders need to be competitive in a market that, for some species at least, is truly international - they need to be able to produce animals that farmers want to buy. Livestock farmers also have to be profitable and competitive, and therefore they will turn to breeders who can provide them with the animals that best serve this purpose. Consequently, traits directly raising productivity and/or product quality will be the main economic priority for the breeding companies. Just how much other traits can be given consideration depends heavily on economic considerations.

There may be an economic benefit in including some non-production traits, such as those relating to animal health, into breeding goals. But obviously, bringing traits that confer no obvious economic advantage into the breeding goal carries monetary costs (among other things, it may slow down the breeding progress for traits that directly affect producer-income). The question is how to cover these costs. One option is through product-pricing. However, as Appleby et al. (2003) point out, this places a heavy responsibility on the individual consumer at point of sale; and the fact that breeding is only a small part of the food chain may make it difficult to convince the consumer of the desirability of the relevant price rises. Another possibility would be for major processors and retailers of food to focus on ethical issues because of the positive effect this may have on these companies' brands. However, in real life the focus will inevitably be on a few salient parameters that are cheap and/or matter to a broad cross-section of consumers. It is unlikely that the issues we have been discussing can be properly dealt with in this way.

Concerns about the impact of agriculture on animal welfare and the environment are often presented as particular to Europe. These concerns are undoubtedly shared by many around the world, but it is correct to say that they have a greater influence on legislation in Europe than in most other countries; and this means that enterprises based in Europe act under legal regulation that may make European production more costly. Global competitiveness is therefore a key issue. One way to address the cost question is that suggested by Lawrence et al. (2004): to incorporate non-economic values in the breeding index, and to work on the assumption that any additional monetary costs are considered part of the public good and paid for as such. However, in the present climate of international trade politics, this is highly unlikely to happen.

\section{Conclusions}

To address the ethical questions raised by farm animal breeding, one needs to understand both the science and current practice of breeding. In addition, one needs to reflect on the values underlying attitudes to animal 
Danish Centre for Bioethics and Risk Assessment

This is a post-print version of an article published in Journal of Agricultural and Environmental Ethics by Springer Verlag

For more articles on animal ethics, see www.animalethics.net

breeding - those that drive the search for improved productivity, and those that cause other stakeholders, such as animal welfare organisations, to have doubts about that search. Finally, ways of being responsive to ethical issues in farm animal breeding should be considered. In this latter discussion, we must recognise the advantages and problems that breeders face when pursuing change, as well as discussing the conflicting priorities of stakeholders and how these are best addressed.

Breeding companies will play an essential role in developing livestock production of a kind that respects animals, the environment and consumer safety, because breeding decisions critically affect what kinds of animal will be used in farm animal production. On the other hand, the breeders' room for manoeuvre in response to ethical demands may be small, since they are just one link in a competitive food production chain. Although they work (and must work) within economic parameters, breeders need ideally to consider all stakeholders' concerns, and to ensure that they are transparent about which considerations are included or reflected in their breeding goals.

The situation outlined here clearly shows that if sustainability is a serious European aspiration, it will be necessary to create an appropriate economic framework to safeguard the future of European agriculture. In creating this framework, we will need to look beyond short-term profit.

\section{Acknowledgements}

We thank the breeding companies' representatives in the CODE-EFABAR project for helpful comments on an earlier version, and Steen Petersen and Ingela Velander from Danish Slaughterhouses for useful information and inspiration. Thanks are also due to Lars Gjøl Christensen and Paul Robinson for valuable comments on early drafts of the paper.

\section{References}

Appleby, M.C., Cutler, N., Gazzard, J., Goddard, P, Milne, J.A., Morgan, C. and Redfern, A. (2002). What price cheap food? J. Agric. Env. Ethics, 16:395-408.

Christensen, L.G. (1998) Future market and consumer-orientated breeding goals. Acta Agric. Scand., Sect A, Animal Sci., Suppl., 28: 45-53.

FAWC (Farm Animal Welfare Council) 2004. FAWC report on the welfare implications of animal breeding and breeding technologies in commercial agriculture. FAWC, London. 
Danish Centre for Bioethics and Risk Assessment

This is a post-print version of an article published in Journal of Agricultural and Environmental Ethics by Springer Verlag

For more articles on animal ethics, see www.animalethics.net

Duncan, I.J.H and Fraser, D. (1997) Understanding animal welfare. In: Animal Welfare Appleby, M.C. and Hughes, B.O. (eds).

CABI, Oxon., pp 19-31.

Gamborg, C. \& Sandøe, P. Sustainable farm animal breeding: a review. Livestock Production Science. In press.

Kolar, R. and Rusche, B. (2003). Animal welfare aspects of farm animal breeding and reproduction: chances for a sustainable future? Final workshop of the SEFABAR project. Rome 4 September 2003.

Landsudvalget for Svin (2004) Arsberetning 2003: Avl og Opformering.

http://www.danskeslagterier.dk/smcms/Landsudvalget_Svin/Videnscenter/DK_avlssystem/Arsberetn_avl_opf/Index.ht $\mathrm{m} ? \mathrm{ID}=298$

Lawrence, A.B., Conington, J. and Simm, G. (2004). Breeding and animal welfare: practical and theoretical advantages of multitrait selection. Animal Welfare, 13:S191-196.

Rauw W.M., Kanis E., Noordhuizen-Stassen E.N., and Grommers F.J. (1998). Undesirable side effects of selection for high production efficiency in farm animals: a review. Livestock Production Science, 56:15-33

Sandøe, P. and Holtug, N (1998) Ethical aspects of biotechnology. Acta Agric. Scand., Sect. A., Anim. Sci. Suppl., 29:51-58.

The National Committee for Pig Production (2004) Annual Report 2004.

http://www.danskeslagterier.dk/smcms/LU_engelsk/Research_and_dev_lu/Annual_Report/Index.htm?ID=539 